\title{
Sympathomimetic Toxidromes and Other Pharmacological Causes of Acute Hypertension
}

\author{
Andrew King ${ }^{1,2} \cdot$ Mirjana Dimovska $^{1} \cdot$ Luke Bisoski $^{1}$ \\ Published online: 24 February 2018 \\ (C) Springer Science+Business Media, LLC, part of Springer Nature 2018
}

\begin{abstract}
Purpose of Review Acute drug-induced hypertension, sympathomimetic toxicity, and other hyperadrenergic states can be caused by both xenobiotic toxicity and withdrawal. This manuscript is a selective review of the recent literature regarding pharmacologic causes of hypertensive emergencies and other hyperadrenergic states.

Recent Findings We will discuss designer stimulants, alpha $a_{2}$ and baclofen agonist withdrawal, and the clinical entity known as posterior reversible encephalopathy syndrome (PRES). Additionally, we examine the controversial "unopposed alph" phenomenon which may result from use of beta-adrenergic antagonist in the presence of stimulant toxicity.

Summary These topics encompass clinical situations and disease entities that are increasingly encountered and are often either unanticipated or under-recognized.
\end{abstract}

Keywords Sympathomimetic toxidrome $\cdot$ Acute hypertension $\cdot$ Alpha 2 agonist withdrawal $\cdot$ Baclofen withdrawal $\cdot$ Unopposed alpha phenomenon $\cdot$ Posterior reversible leukencephalopathy syndrome

\section{Background}

Acute hypertension and hyperadrenergic states are common medical emergencies. Rapid and accurate identification of the underlying causes optimizes treatment and improves patient outcomes. The changing disease prevalence of certain conditions is making unfamiliar causes of acute hypertension and hyperadrenergic states more common. The types and amounts of xenobiotics employed in clinical practice today are influenced by increasing age in population, prevalence of chronic pain conditions, opioid dependence, drug abuse, and neoplastic conditions. Thus, adverse effects from these "trending" xenobiotics are expected to become more commonplace. This review will focus on increasingly common druginduced causes of acute hypertension and hyperadrenergic

This article is part of the Topical Collection on Hypertension and Emergency Medicine

Andrew King

aking@dmc.org

1 Michigan Regional Poison Control Center, Wayne State University School of Medicine, Detroit, MI, USA

2 Detroit, USA states, including the newest designer recreational stimulants, $\mathrm{alpha}_{2}$ and baclofen agonist withdrawal, and the clinical entity known as posterior reversible encephalopathy syndrome (PRES). Additionally, we will review literature regarding beta-blocker therapy in cocaine and stimulant users.

The sympathomimetic toxidrome is a group of clinical signs and symptoms caused by activation of the sympathetic division of the autonomic nervous system. Signs and symptoms may vary significantly based on an agent's individual pharmacokinetic and pharmacodynamic profile, and classically have characteristic effects on each organ system (see Table 1). Severe hyperthermia portends a poor outcome. Sedative-hypnotic withdrawal can be indistinguishable from sympathomimetic toxicity and can manifest all the aforementioned many of the signs and symptoms seen in Table 1.

While acute hypertension is part of the sympathomimetic toxidrome, it has multiple other pharmacologic causes. Mechanisms underlying the blood pressure response include, but are not limited to, activation of the renin-aldosteroneangiotensin system, peripheral alpha-adrenergic stimulation, central alpha $a_{2}$ receptor antagonism, central alpha ${ }_{2}$ agonist withdrawal, nicotinic receptor agonism, sedative-hypnotic withdrawal (GABA-A and B), mineralocorticoid excess, prostaglandin inhibition, smooth muscle calcium signaling, and nitric oxide inhibition or sequestration. Similarly, any 
Table 1 End-organ effects of the sympathomimetic toxidrome

\begin{tabular}{llll}
\hline Cardiovascular & Neurologic & Psychiatric & Other \\
\hline Hypertension & Altered mental status & Anxiety & Diaphoresis \\
Tachycardia & Nystagmus & Hyperarousal states & Dehydration \\
Myocardial ischemia/infarction & Tremors & Insomnia & Hyponatremia \\
Tachydysrhythmias & Bruxism & Agitation & Rhabdomyolysis \\
Arterial dissections & Stroke & Hallucinations & Disseminated \\
Vasospasm & Intracranial hemorrhage & Paranoia/psychosis & intravascular \\
Stress-induced cardiomyopathy & Posterior reversible & Delusions & coagulation \\
Myocarditis & encephalopathy & Repetitive stereotypic & ARDS \\
& syndrome & movements & Acute kidney injury \\
& Seizures & Reinforcing behaviors & Hyperthermia \\
& & & Inhibits GI motility \\
\hline
\end{tabular}

xenobiotic that affects the absorption, distribution, metabolism, or elimination of drugs that work via the same mechanisms, can also induce acute hypertension. End-organs regularly injured by acute hypertension include the brain, heart, eyes, kidneys, and lungs.

\section{Newer Synthetic “Designer" Stimulants}

\section{Designer Stimulants}

The newest generation of synthetic "designer" stimulant, hallucinogenic, and/or entactogenic xenobiotics are classified into four main categories based on their structures: phenethylamines, piperazines, piperadines, and tryptamines. Recreational use of these substances has increased in recent years. This is likely due to increased availability, affordability, and purity. They may be perceived as both legal to possess and more likely to produce sought-after effects [1••]. The Internet allows for discreet sale and distribution, and a safe place to set up forums for users to share their thoughts, tips, experiences, and advice on use of these drugs.

Basic structures of the designer drugs are demonstrated in Fig. 1.

Phenethylamines, piperazine, piperadines, and tryptamines have various effects on and affinities for the norepinephrine, dopamine, and serotonin systems. In general, stimulants cause biogenic amine release, inhibit reuptake, and inhibit monoamine oxidase. The newest hallucinogens tend to be direct serotonin receptor agonists and the newest entactogens cause serotonin release. Manipulation of various parts of each basic chemical structure can change the molecule's ability to cross membranes, stimulate or inhibit receptors, resist enzymatic degradation, and affect cellular transporters [2-8]. Many of these changes result in functional and physiologic changes reflecting a structure-function relationship. For example, oxidation of an amphetamine's $\beta$-carbon to $\alpha$ ketone, creates the cathinone molecule, increasing the chemical's polarity and decreasing its penetration of the central nervous system (CNS). This modification leads to higher dosing and more profound peripheral effects including end-organ effects. Another example is addition of dihydrofuran or difuran rings to the phenyl group. These<smiles>c1ccc(CN2CCNCC2)cc1</smiles><smiles>[R]NC([R5])C([R])c1c([R2])c([R5])c([R4])c([R3])c1[R2]</smiles><smiles>[R5]c1ccc2[nH]cc(CC([R2])N([R19])[Y19])c2c1[R4]</smiles><smiles>C1CCNCC1</smiles>

D $\mathrm{H}$

Fig. 1 Basic chemical structures of the piperazines (a), phenethylamines (b) tryptamines $(\mathbf{c})$, and piperidine $(\mathbf{d})$. Reprinted with permission from $[1 \cdot \bullet]$ 
additions not only give the molecule the appearance of an insect but also create a chemical with potent $5 \mathrm{HT}_{2}$ and alphaadrenergic properties [7]. An example of this is BromoDragonFLY (See figure 3 from Hill et al.).

\section{Phenethylamines}

Phenethylamines form the basic backbone for a very large class of sympathomimetics seen in Fig. $1[1 \bullet \bullet]$. These agents predominantly cause hyperadrenergic states with various degrees of serotonin toxicity that are correlated with structural modifications. The ring-substituted phenethylamines $2 \mathrm{C}$ - and D-series (methoxylated 2 and 5 positions of the benzene ring) are direct serotonin receptor activators with comparatively less stimulant effects. The benzyl derivatives of this group became popular as NBOMe and other offshoots. Halogenated derivatives strengthen the hallucinogenic potential [6]. Beta-ketonated phenethylamines form the cathinone group which earned the sobriquet "bath salts". A further derivative of B-ketonated substituted methylene diophyphenethylamines include ethylone, MDPV and agents such as $\alpha$ PVP known as "Gravel" and "Flakka". Neurologic effects include agitation, aggression, paranoia, hallucinations, confusion, anxiety, bruxism, delusions, tremors, hyperreflexia and seizures. Cardiovascular effects include hypertension, tachycardia, chest pain, and myocarditis. Reports of severe vasoconstriction suggest that the D-series and benzodifurans ("FLY" and "DragonFLY") have relatively stronger vascular effects than other phenethylamines [7, 9-12]. Some ring-substituted phenethylamines (paramethoxyamphetamine and 4-methyltrioamphetamine) are particularly deadly. Aptly named "Death" and "Flatliner," respectively, exposed patients frequently succumb to severe hyperthermia $[13,14]$. Other effects of phenethylamines include renal failure, hyperthermia, hyponatremia, dehydration, exertional compartment syndrome and acidosis [15].

Figure 2 is taken from $[1 \bullet \bullet]$.

\section{Piperazines}

Piperazines (benzylpiperazine and phenylpiperazines) are another class of stimulant xenobiotics causing a sympathomimetic toxidrome. 1-benzylpiperazine (BZP), an antihelminth, achieved international notoriety in the recent past but its use has fallen. Metabolic acidosis, prolonged QT, seizures, hyponatremia, psychosis, multiorgan failure, and death are reported with benzylpiperazine use [16-19]. Phenylpiperazines appears to be relatively less toxic, yet are known to cause dysphoria, confusion, headache, dissociation, agitation, anxiety, and vomiting [20].

\section{Piperidines}

Piperidines are structurally related to methylphenidate and causes a hyperadrenergic state, which may be complicated by extreme and prolonged psychotic reactions [21]. Other effects include hypertension, rhabdomyolysis, dystonia, tachycardia, tachypnea, euphoria, diaphoresis, bruxism, agitation, hallucinations, insomnia, and leukocytosis [21, 22].

\section{Tryptamines}

Tryptamines are serotonergic and have less effect on norepinephrine and dopaminergic systems. These are the classic hallucinogenic amphetamines that appeared during the 1960s and include DMT, methoxyDMT (foxy-methoxy) and LSD [1・•]. Clinical effects of tryptamines are primarily hallucinogenic rather than stimulant or entactogenic. Patients may present with hyperadrenergic features including hypertension, tachycardia, chest pain, and mydriasis. Death is possible and is caused by hyperthermia, coma, and hallucinations leading to life-threatening behaviors.

\section{Management Considerations for Synthetic "Designer" Drugs}

General management is contingent on meticulous supportive care. The major cause of morbidity and mortality is hyperthermia which should be aggressively diagnosed and managed with direct cooling measures since intoxicated patients with hyperthermia have worse outcomes [23, 24•]. Antipyretics, act by reducing $\mathrm{PGE}_{2}$ concentrations in the hypothalamus and will have no effect on thermogenesis from sympathomimetics. Hyperthermia should be treated by reducing any macro- or micromuscular hyperactivity through sedation and possibly paralysis in addition to active cooling measures. Succinylcholine competes with cocaine for plasma cholinesterase and may prolong effects, thus is relatively contraindicated. Hypertension should be treated if it is the cause of endorgan damage. Drug-induced hypertension often responds to sedation with benzodiazepines. If end-organ toxicity due to hypertension still persists, other pharmacological therapies may be considered. Choice of agent should be dependent on the organ affected. For example, ischemic chest pain or pulmonary edema should be managed with nitroglycerin [25]. Intracranial hemorrhage should be managed with nicardipine and potentially nimodipine for vasospasm.

\section{Personal Insights and Observations}

The diagnosis of "synthetic designer drug intoxication" is frequently used for undifferentiated agitated delirium. Unfortunately, a diagnosis applied in the ED and is frequently carried through to discharge whether it is appropriate or not. Once a patient is given a diagnosis, it may cause premature closure of other investigations and anchoring on the diagnosis. It is important to keep a broad differential diagnosis for these 
<smiles>NCCc1ccccc1</smiles>

Metamfetamine<smiles>CN[C@H](C)Cc1ccccc1</smiles>

2C series<smiles>[R]c1cc(O[Hg])c(CCN)cc1OC</smiles>

D series<smiles>[R]c1cc(O[Hg])c(C[C@@H](C)N)cc1OC</smiles>

BromodragonFLY<smiles>C[C@H](N)Cc1c2ccoc2c(Br)c2ccoc12</smiles>

Amfetamine<smiles>C[C@H](N)Cc1ccccc1</smiles>

MDMA<smiles>CN[C@H](C)Cc1ccc2c(c1)OCO2</smiles><smiles>COc1cc(CCN)c(O[GaH])cc1Br</smiles>

DOB<smiles>COc1cc(C[C@H](C)N)c(O[Hg])cc1Br</smiles>

2C-B-FLY<smiles>NCCc1c2c(c(Br)c3c1OCC3)OCC2</smiles>

Mephedrone<smiles>CN[C@@H](C)C(=O)c1ccc(C)cc1</smiles>

Naphyrone<smiles>CCCC(C(=O)c1ccc2ccccc2c1)N1CCCC1</smiles>

2-AT<smiles>NC1CCc2ccccc2C1</smiles>

Methylone<smiles>CN[C@@H](C)C(=O)c1ccc2c(c1)OCO2</smiles><smiles>C[C@H](N)Cc1ccc2ccoc2c1</smiles>

$\alpha$ PPP<smiles>CC(C(=O)c1ccccc1)N1CCCC1</smiles>

2-AI<smiles>NC1Cc2ccccc2C1</smiles><smiles>NC1Cc2cc3c(cc2C1)OCO3</smiles>

MDPV<smiles>CCC[C@H](C(=O)c1ccc2c(c1)OCO2)N1CCCC1</smiles>

Fig. 2 Skeletal formulae for phenethylamines (note all are presented as the $\mathrm{d}$ stereoisomer irrespective of activity for ease of comparison). Reprinted with permission from $[1 \bullet \cdot]$

patients as many have a number of comorbidities. Table 2 lists a number of missed diagnoses that have been erroneously attributed to synthetic designer drug intoxication.

\section{Alpha $_{2}$ Agonist Withdrawal}

Alpha $(\alpha)_{2}$-adrenergic agonists and imidazolines are commonly prescribed medications with a number of medical and non-medical uses. Over-the-counter imidazolines cause topical vasoconstriction and are used for nasal congestion and eye redness. Clonidine, guanfacine, tizanidine, and dexmedetomidine find use in the treatment of hypertension, opioid withdrawal, attention deficit/hyperactivity disorder, muscle spasms, sedative-hypnotic withdrawal, and procedural sedation. CNS stimulation of $\alpha_{2}$-adrenergic and imidazoline receptors (IR) inhibit the release of norepinephrine, epinephrine, dopamine, serotonin, and gamma-butyric acid (GABA). In the spinal cord, alpha receptor stimulation has an analgesic effect [26]. Peripherally, alpha ${ }_{2}$ receptor stimulation in the sympathetic terminal decreases norepinephrine release. This inhibition of sympathetic outflow is often termed "sympatholysis".

Table 2 Synthetic designer stimulant toxicity mimics

Meningitis

Infectious/Autoimmune Encephalitis

Baclofen/GHB withdrawal (oral or intrathecal)

Status epilepticus (convulsive or nonconvulsive)

Posterior reversible encephalopathy syndrome (PRES)

$\mathrm{Alpha}_{2}$ agonist withdrawal (oral or intrathecal)

$\mathrm{Alpha}_{2}$ antagonist toxicity

Mercury toxicity

Pheochromocytoma

Anticholingeric toxicity

Sedative-hypnotic and ethanol withdrawal

Neuroleptic malignant syndrome, serotonin syndrome

Strychnine toxicity

Thyroid storm

Methylxanthine toxicity 
Physiologic dependence can result from short-term use of $\alpha_{2}$ agonists. Abrupt cessation of clonidine with its subsequent hyperadrenergic withdrawal state is well known [27-30]. Withdrawal symptoms include marked blood pressure elevation (i.e., "rebound hypertension"), tachycardia, diaphoresis, abdominal pain, headache, increased arousal, irritability, anxiety, and agitation. Reported life-threatening complications include myocardial infarction, pulmonary edema, ventricular tachycardia, and vertebral artery dissection [31-34]. A similar withdrawal syndrome can be seen for any of the other $\alpha_{2}$ agents including guanfacine, tizanidine, and dexmedetomidine.

Intrathecal, epidural, and topical clonidine administration is used for controlling chronic pain syndromes. Severe and refractory hyperadrenergic states occur if drug delivery is abruptly interrupted $[35,36]$. For example, Lee and colleagues described the case of a 47-year-old man whose intrathecal pump malfunctioned leading to hypertension, new leftbundle branch block, pulmonary edema requiring noninvasive ventilatory support, and stress-induced cardiomyopathy. The patient was treated with intravenous infusions and boluses of clonidine, nitroglycerin, and diazepam but still required 4 days in the intensive care unit [36].

Dexmedetomidine is FDA-approved for sedation of the "initially intubated and mechanically intubated patient" or "non-intubated patients prior to and/or during surgical and other procedures" (https://www.accessdata.fda.gov/ drugsatfda_docs/label/2013/021038s021lbl.pdf). Once the patent expired in 2013, dexmedetomidine use increased to include off-label indications such as sedative hypnotic withdrawal, ventilator weaning, and opioid withdrawal. Although not a common complication of prolonged sedation [37, 38•], dexmedetomidine withdrawal does occur and is an increasingly recognized issue. Despite manufacturer recommendations to limit its use to less than $24 \mathrm{~h}$, prolonged use occurs [37, 38•] and increases the likelihood for physiologic dependence and subsequent withdrawal $[39,40]$.

\section{Treatment of Alpha 2 Agonist Withdrawal}

Treatment of alpha ${ }_{2}$ agonist withdrawal syndrome focuses on identifying and reversing end-organ damage or dysfunction caused by the elevated blood pressure. The best therapy is to "give back" the drug causing the withdrawal and then slowly taper it off over several days [41]. Early administration of clonidine or a similar agent improves blood pressure for both acute clonidine and dexmedetomidine withdrawal. Substitution of a longer acting oral agent (oral or transcutaneous clonidine for dexmedetomidine infusion) is a frequently used option to wean off a short-acting agent once control has been achieved [39, 42-44]. Alternatively, dexmedetomidine has been successfully used for acute clonidine withdrawal and can be considered when a rapidly acting titratable agent is needed [45]. The hypertension encountered with clonidine withdrawal may be refractory to standard doses of certain antihypertensive medications, including nitroglycerin, nicardipine, and certain beta-blockers. Additional antihypertensive therapy should be chosen based on end organs affected, as discussed previously.

\section{Personal Insights and Observations}

Emergency practitioners who treat patient populations where hypertension is prevalent and poorly controlled frequently encounter markedly elevated blood pressure. A substantial portion of these emergencies may result from medication withdrawal, most frequently clonidine. If alpha ${ }_{2}$ agonist withdrawal is suspected, administering the patient's usual dose and allowing time for the medication to work should help to more adequately control blood pressure. Additional doses of clonidine or similar agents may be required, however keep in mind that large doses of clonidine are associated with sedation and apnea. As noted, when clinically appropriate, benzodiazepines can be quite effective to control symptoms of agitation, and reduce blood pressure.

\section{Baclofen Withdrawal}

Baclofen and gamma hydroxybutyrate are agonists at the GABA-B receptor. GABA-B receptors are G proteincoupled and are located both pre- and postsynaptically. Presynaptic GABA-B receptors prevent $\mathrm{Ca}^{2+}$ influx and as a result, provide feedback inhibition. Postsynaptic receptors increase $\mathrm{K}^{+}$efflux and inhibit signal transduction. Interestingly, baclofen can cause seizures in both overdose and withdrawal. In overdose, presynaptic stimulation prevents release of inhibitory neurotransmitters. In withdrawal, there is loss of postsynaptic tonic inhibition resulting in a lack of inhibitory tone.

Baclofen withdrawal can be clinically indistinguishable from a sympathomimetic toxidrome, serotonin syndrome, or other GABAergic withdrawal syndromes. Similar to $\mathrm{alpha}_{2}$ agonist intrathecal pumps, intrathecal baclofen pump malfunction can lead to life-threatening overdose and withdrawal states. In withdrawal, hypertension, tachycardia, stress cardiomyopathy, diaphoresis, spasticity, dystonia, seizures, fever, anxiety, delirium, rhabdomyolysis, DIC and death are reported [46-49, 50••, 51, 52]. Accidental intrathecal overdose can cause seizures, coma, and hemodynamic instability, and it may be difficult to differentiate overdose from withdrawal. If intrathecal overdose is suspected, the airway should be secured, the pump should be emptied immediately through the percutaneous port, and CSF drug aspiration should be considered after consultation with the prescribing clinician $[50 \bullet \cdot$. Good supportive care is the backbone of treatment for both overdose and withdrawal. In withdrawal states, oral baclofen, intravenous benzodiazepines, 
propofol, and dexmedetomidine are reasonable options for symptom control [50••, 53, 54].

\section{Personal Insights and Observations}

Chronic pain is common and, in the setting of the current opioid crisis, providers will increasingly look for opioidsparing options. Some of these options may include "muscle relaxers" such as tizanidine or baclofen orally and/or intrathecally. Most patients do not list intrathecal pump medication as part of their medication list and may be unaware of what the pump is infusing. The only clue to intrathecal overdose or withdrawal may be the characteristic scar and lump on physical examination. This is a reminder to consider nontraditional medication administration. Unless the clinician specifically asks about this medication or performs a comprehensive physical exam, it is an easily missed diagnosis.

\section{Classic Drugs of Abuse}

Cocaine, amphetamines, and amphetamine derivatives have historically been the most widely consumed illegal stimulants in the USA and their clinical effects and associated hyperadrenergic toxidromes are well known. Because these substances cause disease by overstimulation of the adrenergic system (among others), a logical therapeutic approach would be to block the overstimulated receptors causing the disease state. However, animal studies and a few case reports demonstrated the potential for harm with this method, and the putative mechanism was termed the "phenomena of unopposed alpha stimulation." An oversimplified view of the pathophysiology underlying the "unopposed alpha phenomena" generally involves the administration of a nonselective beta-adrenergic antagonist to an individual in a hyperadrenergic state. The vasodilatory effects of the beta ${ }_{2}$ adrenergic stimulation by the agent is lost or "blocked" in the systemic and coronary circulation. In turn, the body is unable to counteract the opposing vasoconstricting effect of postsynaptic alpha ${ }_{1}$ and alpha ${ }_{2}$ agonism that persists. Thus, the alpha agonism is "unopposed" and can lead to profound hypertension and coronary ischemia.

Though the "unopposed alpha" phenomenon is a common teaching and feared adverse drug event, it is based on a few case reports, animal models, and small prospective studies. Recent publications have questioned the quality of the evidence that serves as the foundation for this claim $\left[55^{\bullet}, 56^{\bullet}\right.$, $57 \bullet, 58 \bullet, 59 \bullet, 60 \bullet, 61 \bullet, 62 \bullet$ ]. Richards et al. performed the most recent review of the literature regarding the "unopposed alpha" phenomenon and the reader is referred to its table of contents and summary of literature and evidence grade [62・•].

Table 3 summarizes the studies and cases of cocaine use and beta-blockers and includes descriptions of the adverse outcomes in each reference [62••]. Adverse outcomes were documented in only 7 of 2124 patients and included increased coronary vascular resistance with decreased coronary blood flow, attenuated increases in heart rate and blood pressure, myocardial infarction, worsened pulmonary edema, and cardiac arrest. Notably, these instances were rare, inconsistent, and difficult to differentiate from the adverse effects of cocaine itself. Of note, there were no adverse events attributed to the unopposed alpha phenomenon when combined alpha/beta antagonists were used (i.e., labetalol and carvedilol).

There are also case reports showing potential beneficial effects of beta bockers in acute sympathomimetic intoxication. These include improvement of blood pressure with IV propranolol and labetalol in the setting of intentional overdose of pseudoephedrine and ephedrine, improvement of injury pattern on ECG with administration of metoprolol in the setting of pseudoephedrine toxicity, and lower heart rates with no change in blood pressure when MDMA users were pretreated with pindolol [63-66]. Larger, retrospective studies report beta-adrenergic antagonist therapy either does not cause harm or may even show benefit. A retrospective review of 307 admitted patients with cocaine present on their urine drug screens reported that the 60 who received beta-blockers had a lower risk of myocardial infarction than those who did not receive beta-blockers [67•]. Hoskins et al. analyzed patients with acute coronary syndrome and urine drug screen positive for cocaine treated with either labetalol or diltiazem showed that subjects who received labetalol had lower serum inflammatory markers when compared to the diltiazem group and both groups had decreases in blood pressure [68]. A study by Ibrahim et al., evaluated patients presenting with chest pain and positive cocaine urine drug screens with elevated troponins. Subjects were administered either beta1-selective or mixed $\alpha_{1} /$ beta-blockers and the investigators found no association with higher troponin levels in either group. No cases of hypertensive urgency were identified in any patient that received beta-blockers [69•]. Finally, a study by Rangel et al. found that patients with cocaine-associated chest pain discharged on a beta-blocker had a lower risk for cardiovascular death [70•].

Reviews have concluded that while the evidence of harm remains limited, the use of selective beta-blockers to control acute chest pain and hypertension as a first-line therapy is not recommended. Other effective agents that do not carry the same potential risks exist and the appropriate comparison studies do not exist [59•]. Schurr et al. sums up the inconsistencies in the evidence: "current literature is limited but suggests that beta-adrenergic antagonists are harmful. Although case reports support a detrimental effect of beta-adrenergic antagonists, the anecdotal data are inconsistent, and the conclusions from case studies are overruled by larger studies". [61•]. 


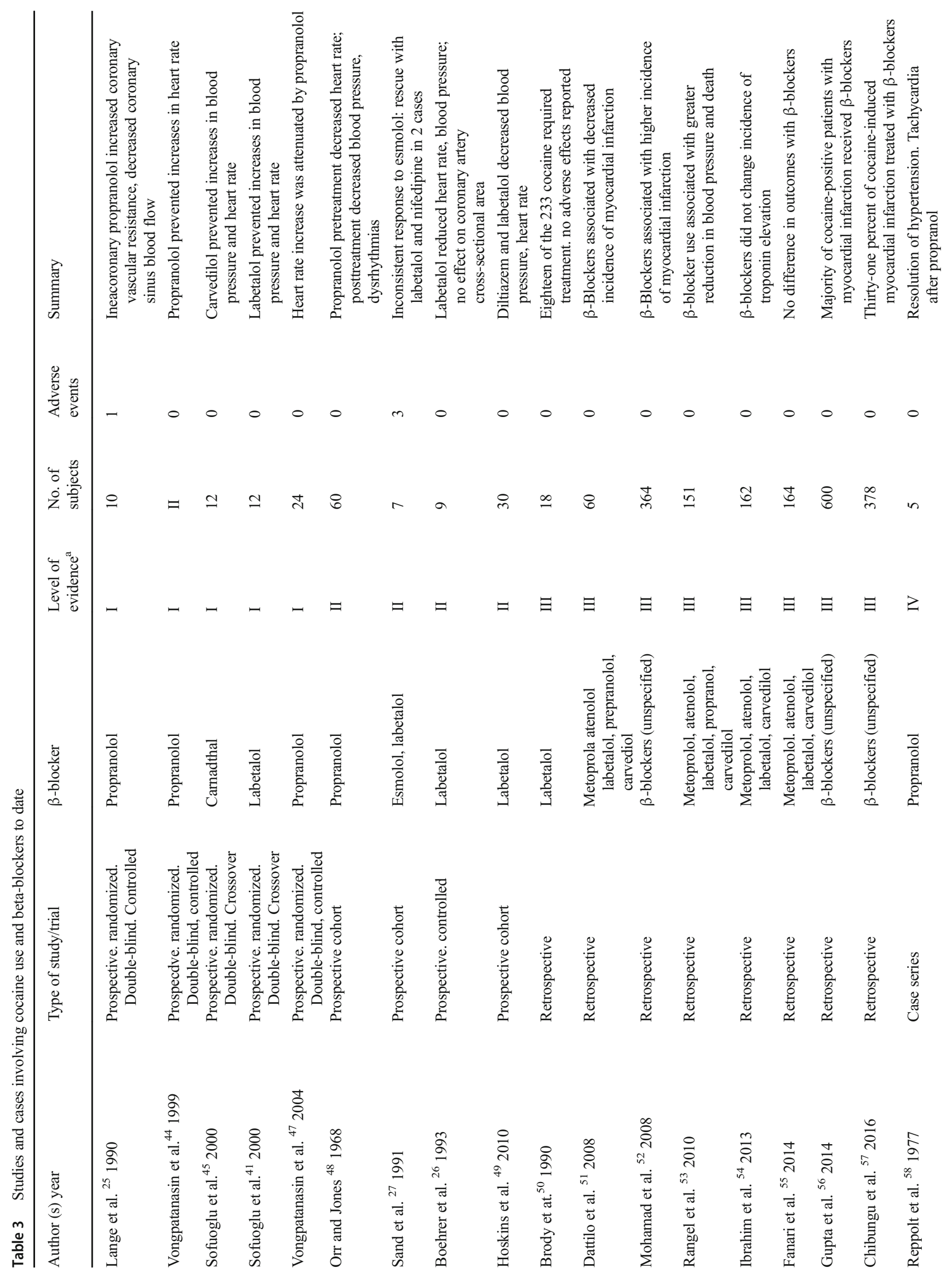




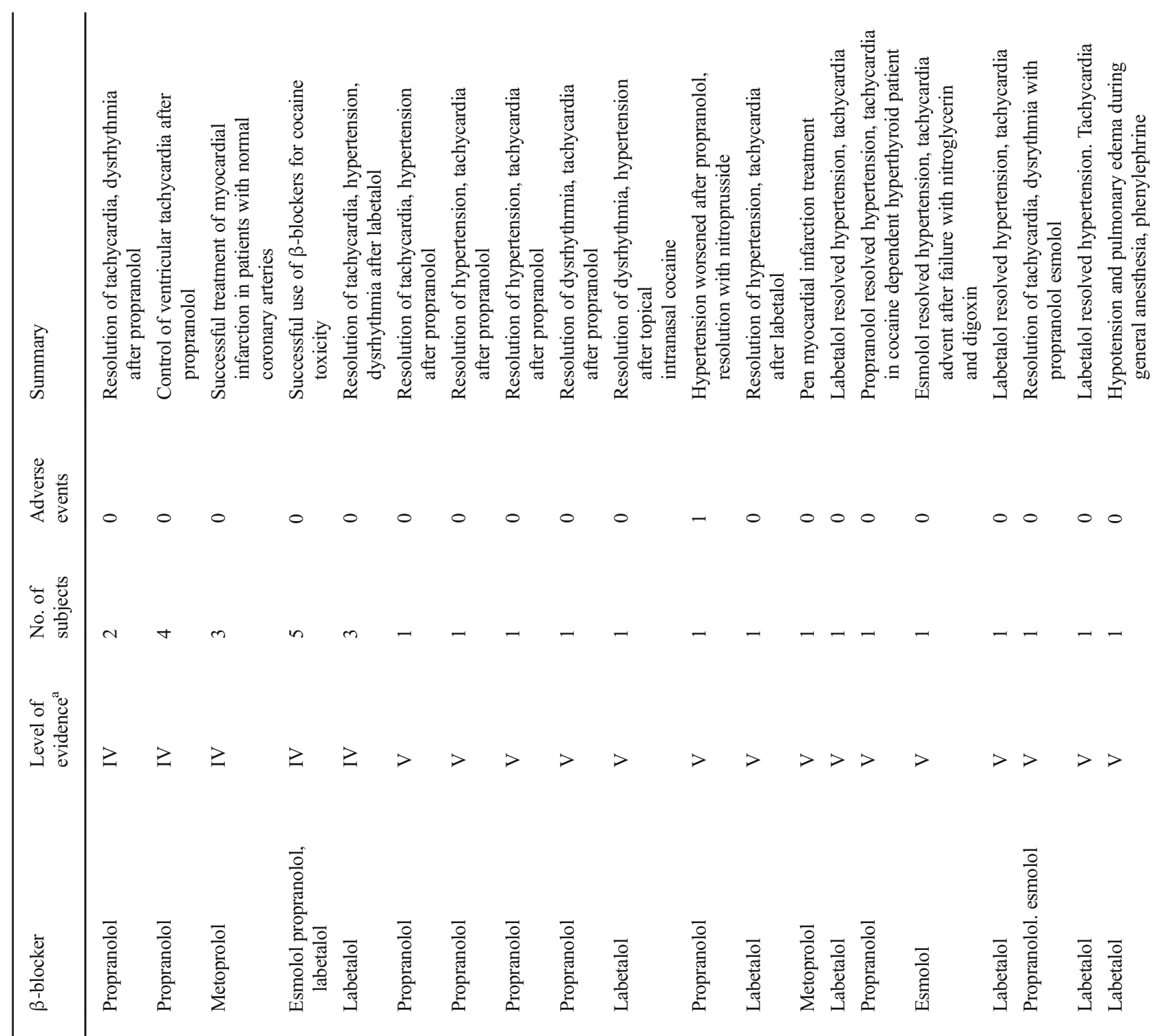

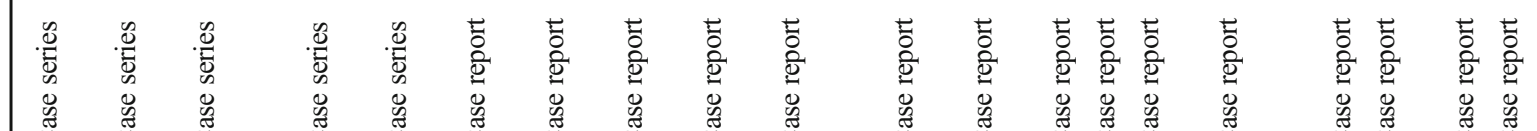

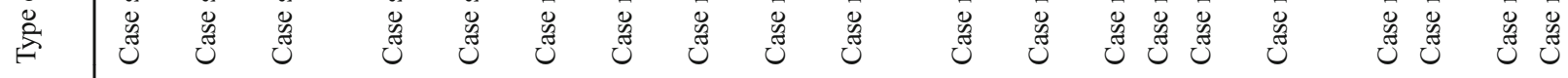

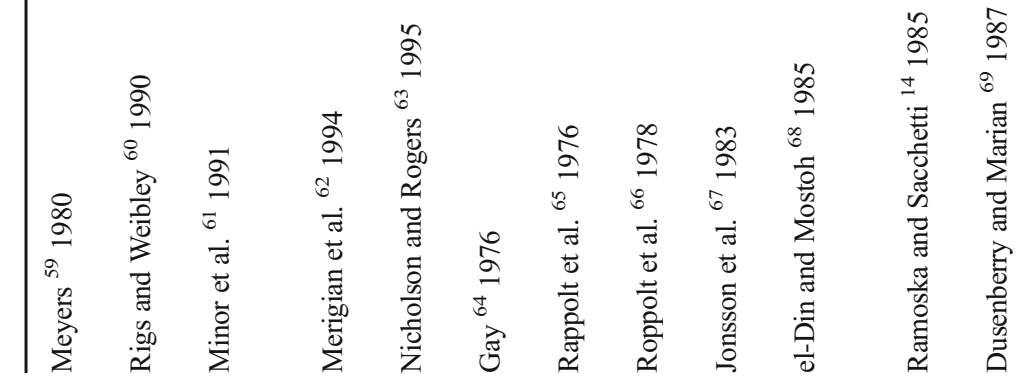

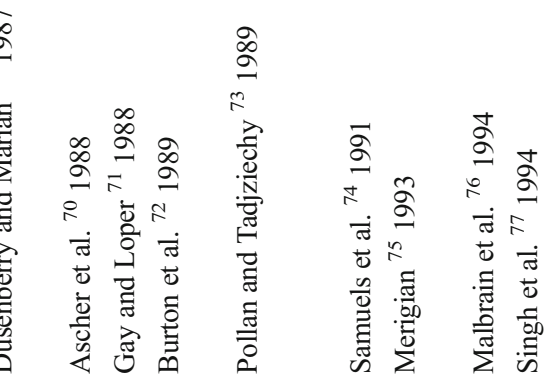




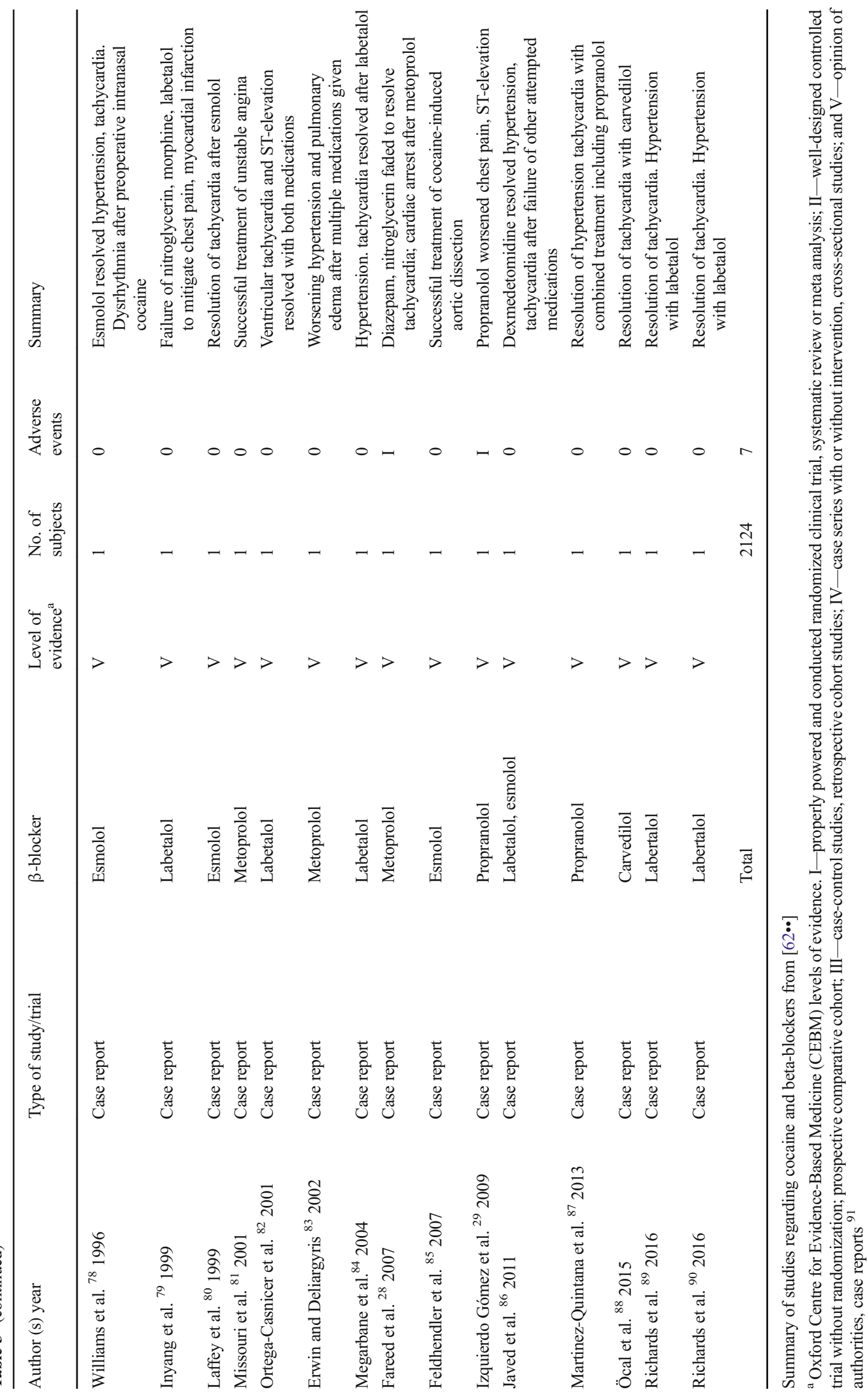




\section{Management}

General management of patients presenting with cocaine and amphetamine associated cardiovascular effects involves decreasing the hyperadrenergic state and agitation with benzodiazepines, as well as controlling blood pressure with nitrates and/or calcium channel blockers. A few prospective studies have been performed attempting to define the optimal treatment regimen. The combination of lorazepam with nitroglycerin versus nitroglycerin alone in one study was more effective in reducing chest pain [71••]. However, another reported that in patients with cocaine-associated acute coronary syndrome treated with nitroglycerin, diazepam, or both, did not demonstrate any difference with regard to therapy in terms of chest pain, and other hemodynamic and cardiac profiles [72•]. A systematic literature review performed by Richards et al. also graded the evidence for management of cocaine cardiovascular toxicity with regards benzodiazepines, calcium channel blockers, nitric-oxide-mediated vasodilators, alphablockers, alpha2 agonists, and beta-blockers [62••].

\section{Personal Insights and Observations}

The documented adverse effects and outcomes of patients administered beta-adrenergic antagonists suggest the possibility of harm; however, these observations are rare and inconsistent. In vivo cardiac catheterization studies demonstrate the potential for coronary vasoconstriction but are difficult to generalize, while larger studies of beta-blockers in cocaine users demonstrate benefit. Unfortunately, it is easy to remember case stories rather than study results, and the practice of medicine based on dramatic case reports often supersedes more robust and reliable data. That being said, it is entirely possible that selective beta blockade is harmful as suggested by case reports when patients are acutely toxic. The larger studies may or may not include or capture the acutely toxic patients with their inclusion criteria. Much of this is a non-issue. Alternative non-stigmatized medications exist and are effectively employed to stabilize the acutely hyperadrenergic patient.

\section{Posterior Reversible Encephalopathy Syndrome}

Posterior reversible encephalopathy syndrome (PRES) or reversible posterior leukoencephalopathy syndrome (RPLS), first described in 1996, seems to be associated with certain xenobiotics [73]. PRES is characterized by a reversible constellation of findings and symptoms including headache, hypertension, altered mental status, seizures, vision loss, and posterior leukoencephalopathy seen on imaging $[73,74,75 \bullet \bullet, 76,77]$. Blood pressure elevations are usually critically high, with a mean of $199 / 104 \mathrm{mmHg}$ in one case series [74]. Risk factors include autoimmune disease, renal failure, and hypertension. PRES has occurred in the aftermath of sympathomimetic toxicity but more commonly associated with immunosuppressant agents and chemotherapy medications [77-80, 81・, 82].

There are multiple yet unproven theories regarding the pathogenesis of PRES, and the extent to which xenobiotics play a causal role remains unclear [76]. The "vasogenic" theory involves a rapid increase in systemic vascular resistance that overwhelms cerebral autoregulation resulting in hyperperfusion, increased hydrostatic pressure, and capillary leak with vasogenic edema. The "cytotoxic" theory purports the xenobiotics used in chemotherapy and immunomodulatory therapy cause endothelial dysfunction and cerebral edema. The "neuropeptide theory" argues vasoconstrictors such as endothelin1 , prostacyclin, and thromboxane $\mathrm{A}_{2}$ induce vasospasm, ischemia, and subsequent edema. The "immunogenic theory" posits T cell activation and cytokine release to cause increased cellular permeability.

\section{Treatment of PRES}

Recommended treatment for PRES includes blood pressure control as well as discontinuation of any associated medications. Seizures should be rapidly halted and may require antiepileptic medications. Although there are no studies on blood pressure control and its effect on resolution of PRES, hypertension treatment is generally thought to be important. In severe hypertension, reducing pressure by $25 \%$ in the first hours is reasonable. There is no specific agent preferred in PRES. Patients tend to have a good prognosis when treated quickly and $75-90 \%$ of patients have complete recoveries [75••].

\section{Personal Inights and Observations}

PRES is another disease process in which a high degree of suspicion is needed to make the diagnosis. Once seizure activity is controlled and subsequent catecholamine surge, patients may have persistent hypertension. It is often unclear how aggressive one should be with blood pressure control in this situation. On the one hand, rapid lowering of blood pressure may result in watershed infarct but on the other, as in the case of PRES, more aggressive control may be warranted. Rapid and emergent access to MRI to help confirm the diagnosis may not be available in all institutions. Regardless, the diagnosis should be entertained in the setting of patients with hypertension, seizures, and/or altered mental status and an unremarkable head CT after immunomodulator or chemotherapeutic use.

\section{Conclusions}

Xenobiotic-induced hypertension and hyperadrenergic states are common medical emergencies. Optimal treatment 
is predicated by the underlying etiology of these states. Designer stimulants will continue to cause toxicity in both predictable and unpredictable ways each time an "untested" compound becomes available. The increasing prevalence of chronic pain syndromes and use of opioid-sparing therapies (e.g. baclofen and intrathecal medication delivery devices) will put an increasing number of patients at risk for lifethreatening withdrawal phenomena either due to medication noncompliance or device malfunction. Diagnosis requires a high index of suspicion. The "unopposed alpha" phenomenon is rare and based on low level evidence. While evidence for harm exists, other studies suggest treatment efficacy and overall benefit when beta-blockers are administered to stimulant users. Regardless, other effective options exist to treat acute stimulant-induced cardiovascular toxicity. Finally, the pathophysiologic underpinnings of PRES remain poorly understood; however, the clinical presentation, associated xenobiotics and risk factors are well established.

\section{Compliance with Ethical Standards}

Conflict of Interest The authors declare no conflicts of interest relevant to this manuscript.

Human and Animal Rights and Informed Consent This article does not contain any studies with human or animal subjects performed by any of the authors.

\section{References}

Papers of particular interest, published recently, have been highlighted as:

- Of importance

•- Of major importance

1.• Hill SL, Thomas SH. Clinical toxicology of newer recreational drugs. Clin Toxicol (Phila). 2011;49(8):705-19. Recent extensive review of available information on synthetic "designer" drugs utilizing peer-reviewed literature to date as well as media and drug user forums, books, and government publications. https:// doi.org/10.3109/15563650.2011.615318.

2. Baumann $\mathrm{MH}$, et al. Effects of "Legal X" piperazine analogs on dopamine and serotonin release in rat brain. Ann N Y Acad Sci. 2004;1025(1):189-97. https://doi.org/10.1196/annals.1316.024.

3. Schep LJ, et al. The clinical toxicology of the designer "party pills" benzylpiperazine and trifluoromethylphenylpiperazine. Clin Toxicol (Phila). 2011;49(3):131-41. https://doi.org/10.3109/ 15563650.2011 .572076$.

4. Cho, A.K. and D.S. Segal, Amphetamine and its analogs : psychopharmacology, toxicology, and abuse. 1994, San Diego: Academic Press. xxi, $503 \mathrm{p}$.

5. Villalobos CA, et al. 4-Bromo-2,5-dimethoxyphenethylamine (2CB) and structurally related phenylethylamines are potent 5-HT2A receptor antagonists in Xenopus laevis oocytes. Br J Pharmacol. 2004;141(7):1167-74. https://doi.org/10.1038/sj.bjp.0705722.

6. Acuna-Castillo $\mathrm{C}$, et al. Differences in potency and efficacy of a series of phenylisopropylamine/phenylethylamine pairs at 5-
HT(2A) and 5-HT(2C) receptors. Br J Pharmacol. 2002;136(4): 510-9. https://doi.org/10.1038/sj.bjp.0704747.

7. Wood DM, et al. Delayed onset of seizures and toxicity associated with recreational use of Bromo-dragonFLY. J Med Toxicol. 2009;5(4):226-9. https://doi.org/10.1007/BF03178273.

8. Meltzer PC, et al. 1-(4-Methylphenyl)-2-pyrrolidin-1-yl-pentan-1one (Pyrovalerone) analogues: a promising class of monoamine uptake inhibitors. J Med Chem. 2006;49(4):1420-32. https://doi. org/10.1021/jm050797a.

9. Bowen JS, et al. Diffuse vascular spasm associated with 4-bromo-2, 5-dimethoxyamphetamine ingestion. JAMA. 1983;249(11):14779. https://doi.org/10.1001/jama.1983.03330350053028.

10. Balikova M. Nonfatal and fatal DOB (2,5-dimethoxy-4bromoamphetamine) overdose. Forensic Sci Int. 2005;153(1):8591. https://doi.org/10.1016/j.forsciint.2005.04.022.

11. Andreasen MF, et al. A fatal poisoning involving Bromo-dragonfly. Forensic Sci Int. 2009;183(1-3):91-6. https://doi.org/10.1016/j. forsciint.2008.11.001.

12. Thorlacius K, Borna C, Personne M. Bromo-dragon fly-lifethreatening drug. Can cause tissue necrosis as demonstrated by the first described case. Lakartidningen. 2008;105(16):1199-200.

13. Lamberth PG, Ding GK, Nurmi LA. Fatal paramethoxyamphetamine (PMA) poisoning in the Australian Capital Territory. Med J Aust. 2008;188(7):426.

14. Carmo H, et al. CYP2D6 increases toxicity of the designer drug 4methylthioamphetamine (4-MTA). Toxicology. 2007;229(3):236 44. https://doi.org/10.1016/j.tox.2006.10.024.

15. Levine M, Levitan R, Skolnik A. Compartment syndrome after "bath salts" use: a case series. Ann Emerg Med. 2013;61(4):480 3. https://doi.org/10.1016/j.annemergmed.2012.11.021.

16. Elliott $\mathrm{S}$, Smith $\mathrm{C}$. Investigation of the first deaths in the United Kingdom involving the detection and quantitation of the piperazines BZP and 3-TFMPP. J Anal Toxicol. 2008;32(2):172-7. https://doi.org/10.1093/jat/32.2.172.

17. Gee P, Jerram T, Bowie D. Multiorgan failure from 1benzylpiperazine ingestion - legal high or lethal high? Clin Toxicol (Phila). 2010;48(3):230-3. https://doi.org/10.3109/ 15563651003592948.

18. Gee P, et al. Toxic effects of BZP-based herbal party pills in humans: a prospective study in Christchurch, New Zealand. N Z Med J. 2005;118(1227):U1784.

19. Austin H, Monasterio E. Acute psychosis following ingestion of "Rapture". Australas Psychiatry. 2004;12(4):406-8. https://doi. org/10.1080/j.1440-1665.2004.02137.x.

20. Thompson I, et al. Randomised double-blind, placebo-controlled trial of the effects of the "party pills" BZP/TFMPP alone and in combination with alcohol. J Psychopharmacol. 2010;24(9):1299_ 308. https://doi.org/10.1177/0269881109102608.

21. Wood DM, Dargan PI. Use and acute toxicity associated with the novel psychoactive substances diphenylprolinol (D2PM) and desoxypipradrol (2-DPMP). Clin Toxicol (Phila). 2012;50(8): 727-32. https://doi.org/10.3109/15563650.2012.716158.

22. Murray DB, et al. 'Ivory wave' toxicity in recreational drug users; integration of clinical and poisons information services to manage legal high poisoning. Clin Toxicol (Phila). 2012;50(2):108-13. https://doi.org/10.3109/15563650.2011.647992.

23. Rosenberg J, et al. Hyperthermia associated with drug intoxication. Crit Care Med. 1986;14(11):964-9. https://doi.org/10.1097/ 00003246-198611000-00011.

24. Rusyniak DE, Sprague JE. Toxin-induced hyperthermic syndromes. Med Clin North Am. 2005;89(6):1277-96. Review of toxin-induced hyperthermia syndromes related to appropriate diagnosis and treatment of these conditions. https://doi.org/10. 1016/j.mena.2005.06.002.

25. Levy P, et al. Treatment of severe decompensated heart failure with high-dose intravenous nitroglycerin: a feasibility and outcome 
analysis. Ann Emerg Med. 2007;50(2):144-52. https://doi.org/10. 1016/j.annemergmed.2007.02.022.

26. Eisenach JC, De Kock M, Klimscha W. Alpha(2)-adrenergic agonists for regional anesthesia. A clinical review of clonidine (19841995). Anesthesiology. 1996;85(3):655-74. https://doi.org/10. 1097/00000542-199609000-00026.

27. Simic J, et al. Acute myocardial infarction as a complication of clonidine withdrawal. J Emerg Med. 2003;25(4):399-402. https:// doi.org/10.1016/j.jemermed.2003.04.002.

28. Reid JL, Campbell BC, Hamilton CA. Withdrawal reactions following cessation of central alpha-adrenergic receptor agonists. Hypertension. 1984;6(5 Pt 2):II71-5.

29. Sarlis NJ, et al. Hyperadrenergic state following acute withdrawal from clonidine used at supratherapeutic doses. Clin Auton Res. 1996;6(2):115-7. https://doi.org/10.1007/BF02291233.

30. Leckman JF, et al. Rebound phenomena in Tourette's syndrome after abrupt withdrawal of clonidine. Behavioral, cardiovascular, and neurochemical effects. Arch Gen Psychiatry. 1986;43(12): 1168-76. https://doi.org/10.1001/archpsyc.1986.01800120054011.

31. Berge KH, Lanier WL. Myocardial infarction accompanying acute clonidine withdrawal in a patient without a history of ischemic coronary artery disease. Anesth Analg. 1991;72(2):259-61. https://doi.org/10.1213/00000539-199102000-00023.

32. Jain P, Misra A. Non-sustained ventricular tachycardia following clonidine withdrawal. Postgrad Med J. 1991;67(786):403-4. https://doi.org/10.1136/pgmj.67.786.403.

33. Abrich V, Martin P, Hennick M. Vertebral artery dissection and lateral medullary stroke associated with neck trauma and clonidine withdrawal. N Am J Med Sci. 2013;5(7):443-4. https://doi.org/10. 4103/1947-2714.115767.

34. Shaw M, Matsa R. Clonidine withdrawal induced sympathetic surge. BMJ Case Rep. 2015;2015

35. Fitzgibbon D, et al. Rebound hypertension and withdrawal associated with discontinuation of an infusion of epidural clonidine. Anesthesiology. 1996;84(3):729-31. https://doi.org/10.1097/ 00000542-199603000-00031.

36. Lee HM, Ruggoo V, Graudins A. Intrathecal clonidine pump failure causing acute withdrawal syndrome with 'Stress-Induced' cardiomyopathy. J Med Toxicol. 2016;12(1):134-8. https://doi.org/10. 1007/s13181-015-0505-9.

37. Gupta P, et al. Safety and efficacy of prolonged dexmedetomidine use in critically ill children with heart disease. Pediatr Crit Care Med. 2012;13(6):660-6. https://doi.org/10.1097/PCC. 0b013e318253c7f1.

38. Shehabi Y, et al. Dexmedetomidine infusion for more than 24 hours in critically ill patients: sedative and cardiovascular effects. Intensive Care Med. 2004;30(12):2188-96. Helpful review of alpha agonist $_{2}$ withdrawal in the form of an editorial, discussing the possibility of tolerance and withdrawal from an ICU physician perspective. https://doi.org/10.1007/s00134-004-2417-z.

39. Kukoyi A, et al. Two cases of acute dexmedetomidine withdrawal syndrome following prolonged infusion in the intensive care unit: report of cases and review of the literature. Hum Exp Toxicol. 2013;32(1):107-10. https://doi.org/10.1177/0960327112454896.

40. Weber MD, Thammasitboon S, Rosen DA. Acute discontinuation syndrome from dexmedetomidine after protracted use in a pediatric patient. Paediatr Anaesth. 2008;18(1):87-8. https://doi.org/10. 1111/j.1460-9592.2007.02377.x.

41. Houston MC. Treatment of hypertensive emergencies and urgencies with oral clonidine loading and titration. A review. Arch Intern Med. 1986;146(3):586-9. https://doi.org/10.1001/archinte.1986. 00360150236029 .

42. Gagnon DJ, et al. Transition from dexmedetomidine to enteral clonidine for ICU sedation: an observational pilot study. Pharmacotherapy. 2015;35(3):251-9. https://doi.org/10.1002/phar.1559.
43. Lardieri $\mathrm{AB}$, et al. Effects of clonidine on withdrawal from long-term dexmedetomidine in the pediatric patient. J Pediatr Pharmacol Ther. 2015;20(1):45-53. https://doi.org/10.5863/1551-6776-20.1.45.

44. Tobias JD. Dexmedetomidine: are tolerance and withdrawal going to be an issue with long-term infusions? Pediatr Crit Care Med. 2010;11(1):158-60. https://doi.org/10.1097/PCC.0b013e3181ae49af.

45. Bowcock E, Morris I, Lane A. Dexmedetomidine for acute clonidine withdrawal following intrathecal pump removal: a drug beginning to find its expanding niche. J Intensive Care Soc. 2016;17(3): 271-2. https://doi.org/10.1177/1751143716638374.

46. Awuor SO, et al. Intrathecal baclofen withdrawal: a rare cause of reversible cardiomyopathy. Acute Card Care. 2016;18(1):13-7. https://doi.org/10.3109/17482941.2016.1174273.

47. Cardoso AL, Quintaneiro C, Seabra H, Teixeira C. Cardiac arrest due to baclofen withdrawal syndrome. BMJ Case Rep. 2014. https://doi.org/10.1136/bcr-2014-204322.

48. D'Aleo $\mathrm{G}$, et al. Hallucinations after abrupt withdrawal of oral and intrathecal baclofen. Funct Neurol. 2007;22(2):81-8.

49. Stetkarova I, et al. Intrathecal baclofen in spinal spasticity: frequency and severity of withdrawal syndrome. Pain Physician. 2015;18(4):E633-41.

$50 . \bullet$ Watve SV, et al. Management of acute overdose or withdrawal state in intrathecal baclofen therapy. Spinal Cord. 2012;50(2):107-11. Recent review of studies relevant to the management of patients with intrathecal baclofen overdose and withdrawal. https://doi. org/10.1038/sc.2011.112.

51. Specchio N, et al. Prolonged episode of dystonia and dyskinesia resembling status epilepticus following acute intrathecal baclofen withdrawal. Epilepsy Behav. 2011;21(3):321-3. https://doi.org/10. 1016/j.yebeh.2011.04.052.

52. Kao LW, et al. Intrathecal baclofen withdrawal mimicking sepsis. $\mathrm{J}$ Emerg Med. 2003;24(4):423-7. https://doi.org/10.1016/S07364679(03)00039-8.

53. Morr S, et al. Dexmedetomidine for acute baclofen withdrawal. Neurocrit Care. 2015;22(2):288-92. https://doi.org/10.1007/ s12028-014-0083-8.

54. Greenberg MI, Hendrickson RG. Baclofen withdrawal following removal of an intrathecal baclofen pump despite oral baclofen replacement. J Toxicol Clin Toxicol. 2003;41(1):83-5. https://doi. org/10.1081/CLT-120018277.

55. Finkel JB, Marhefka GD. Rethinking cocaine-associated chest pain and acute coronary syndromes. Mayo Clin Proc. 2011;86(12): 1198-207. Review of cocaine-associated chest pain and betablocker use from a unique author's perspective. $h$ ttps://doi.org/ 10.4065/mcp.2011.0338.

56. Freeman K, Feldman JA. Cocaine, myocardial infarction, and betablockers: time to rethink the equation? Ann Emerg Med. 2008;51(2):130-4. Review of cocaine-associated chest pain and beta-blocker use from a unique author's perspective. https://doi. org/10.1016/j.annemergmed.2007.08.020.

57. Leikin JB. Cocaine and beta-adrenergic blockers: a remarriage after a decade-long divorce? Crit Care Med. 1999;27(4):688-9. Review of cocaine-associated chest pain and beta-blocker use from a unique author's perspective. $\mathrm{https} / / /$ doi.org/10.1097/00003246199904000-00012.

58. Mariani PJ. Beta-blockers following cocaine use: a reappraisal. Ann Emerg Med. 2008;52(1):89; author reply 89-90. Review of cocaine-associated chest pain and beta-blocker use from a unique author's perspective. https://doi.org/10.1016/j. annemergmed.2007.11.048.

59. Page RL II, Utz KJ, Wolfel EE. Should beta-blockers be used in the treatment of cocaine-associated acute coronary syndrome? Ann Pharmacother. 2007;41(12):2008-13. Review of cocaineassociated chest pain and beta-blocker use from a unique author's perspective. $h$ ttps://doi.org/10.1345/aph.1H643. 
60. Richards JR, et al. Beta-blockers, cocaine, and the unopposed alpha-stimulation phenomenon. J Cardiovasc Pharmacol Ther. 2017;22(3):239-49. Review of cocaine-associated chest pain and beta-blocker use from a unique author's perspective. https://doi.org/10.1177/1074248416681644.

61. Schurr JW, Gitman B, Belchikov Y. Controversial therapeutics: the beta-adrenergic antagonist and cocaine-associated cardiovascular complications dilemma. Pharmacotherapy. 2014;34(12):1269-81. Review of cocaine-associated chest pain and beta-blocker use from a unique author's perspective. $h$ ttps://doi.org/10.1002/phar. 1486.

62.• Richards JR, et al. Treatment of cocaine cardiovascular toxicity: a systematic review. Clin Toxicol (Phila). 2016;54(5):345-64. Most extensive and recent review on available evidence regarding the treatment of cocaine-related cardiovascular toxicity to date. https://doi.org/10.3109/15563650.2016.1142090.

63. Hysek CM, Vollenweider FX, Liechti ME. Effects of a beta-blocker on the cardiovascular response to MDMA (Ecstasy). Emerg Med J. 2010;27(8):586-9. https://doi.org/10.1136/emj.2009.079905.

64. Burkhart KK. Intravenous propranolol reverses hypertension after sympathomimetic overdose: two case reports. J Toxicol Clin Toxicol. 1992;30(1):109-14. https://doi.org/10.3109/ 15563659208994450.

65. Rappolt RT Sr, et al. Treatment plan for acute and chronic adrenergic poisoning crisis utilizing sympatholytic effects of the B1-B2 receptor site blocker propranolol (Inderal) in concert with diazepam and urine acidification. Clin Toxicol. 1979;14(1):55-69. https://doi. org/10.3109/15563657909030114.

66. Akay S, Ozdemir M. Acute coronary syndrome presenting after pseudoephedrine use and regression with beta-blocker therapy. Can J Cardiol. 2008;24(11):e86-8. https://doi.org/10.1016/S0828282X(08)70200-9.

67. Dattilo PB, Hailpern SM, Fearon K, Sohal D, Nordin C. Betablockers are associated with reduced risk of myocardial infarction after cocaine use. Ann Emerg Med. 2008;51(2):117-25. Retrospective cohort study demonstrating an association of reduced risk for MI in patients with positive drug screens for cocaine who received beta blockade during admission. https:// doi.org/10.1016/j.annemergmed.2007.04.015.

68. Hoskins MH, et al. Effects of labetalol on hemodynamic parameters and soluble biomarkers of inflammation in acute coronary syndrome in patients with active cocaine use. J Cardiovasc Pharmacol Ther. 2010;15(1):47-52. https://doi.org/10.1177/ 1074248409358409.

69. Ibrahim M, Maselli DJ, Hasan R, Hamilton A. Safety of betablockers in the acute management of cocaine-associated chest pain. Am J Emerg Med. 2013;31(3):613-6. Retrospective chart review of patients with cocaine-associated chest pain showing no increase in troponin in patients who received beta blockers during admission compared to those who did not. https://doi.org/10. 1016/j.ajem.2012.09.027.

70. Rangel C, et al. Beta-blockers for chest pain associated with recent cocaine use. Arch Intern Med. 2010;(10):170, 874-9. Retrospective review of patients with positive urine drug screen for coccaine comparing those who received a beta-blocker with those who did not, showing no association with adverse event.

71.• Honderick T, Williams D, Seaberg D, Wears R. A prospective, randomized, controlled trial of benzodiazepines and nitroglycerine or nitroglycerine alone in the treatment of cocaine-associated acute coronary syndromes. Am J Emerg Med. 2003;21(1):39-42. Basis of the evidence for benzodiazepine use in cocaine-associated chest pain. Randomized controlled trial showing improvement in pain in patients who received lorazepam + nitroglycerine vs nitroglycerin alone. $h$ ttps://doi.org/10.1053/ajem.2003.50010.

72. Baumann BM, Perrone J, Hornig SE, Shofer FS, Hollander JE. Randomized, double-blind, placebo-controlled trial of diazepam, nitroglycerin, or both for treatment of patients with potential cocaine-associated acute coronary syndromes. Acad Emerg Med. 2000;7(8):878-85. Randomized controlled trial showing no difference in diazepam + nitroglycerin versus nitroglycerin alone in the resolution chest pain or changes in stroke index. https:// doi.org/10.1111/j.1553-2712.2000.tb02065.x.

73. Hinchey J, Chaves C, Appignani B, Breen J, Pao L, Wang A, et al. A reversible posterior leukoencephalopathy syndrome. N Engl J Med. 1996;334(8):494-500. https://doi.org/10.1056/ NEJM199602223340803.

74. Fugate JE, Claassen DO, Cloft HJ, Kallmes DF, Kozak OS, Rabinstein AA. Posterior reversible encephalopathy syndrome: associated clinical and radiologic findings. Mayo Clin Proc. 2010;85(5):427-32. https://doi.org/10.4065/mcp.2009.0590.

75.• Fugate JE, Rabinstein AA. Posterior reversible encephalopathy syndrome: clinical and radiological manifestations, pathophysiology, and outstanding questions. Lancet Neurol. 2015;14(9):914-25. Most recent and comprehensive review regarding etiology, diagnosis, and treatment of PRES to date. https://doi.org/10.1016/ S1474-4422(15)00111-8.

76. Granata G, et al. Posterior reversible encephalopathy syndromeinsight into pathogenesis, clinical variants and treatment approaches. Autoimmun Rev. 2015;14(9):830-6. https://doi.org/10. 1016/j.autrev.2015.05.006.

77. Zekic T, et al. The multifactorial origin of posterior reversible encephalopathy syndrome in cyclophosphamide-treated lupus patients. Rheumatol Int. 2017;37(12):2105-14. https://doi.org/10. 1007/s00296-017-3843-x.

78. Gharabawy R, et al. Epinephrine-induced posterior reversible encephalopathy syndrome: a case report. J Clin Anesth. 2011;23(6): 505-7. https://doi.org/10.1016/j.jclinane.2010.12.017.

79. Jayaweera JL, et al. Cyclophosphamide-induced posterior reversible encephalopathy syndrome (PRES): a case report. J Med Case Rep. 2014;8(1):442. https://doi.org/10.1186/1752-1947-8-442.

80. Omer TA, Doherty C. Posterior reversible encephalopathy syndrome (PRES) complicating the 'legal high' mephedrone. BMJ Case Rep. 2011;2011

81. Song T, Rao Z, Tan Q, Qiu Y, Liu J, Huang Z, et al. Calcineurin inhibitors associated posterior reversible encephalopathy syndrome in solid organ transplantation: report of 2 cases and literature review. Medicine (Baltimore). 2016;95(14):e3173. Good recent review and report of current understanding regarding the connection between PRES and 2 of its most commonly associated agents. https://doi.org/10.1097/MD.0000000000003173.

82. Wang W, Zhao LR, Lin XQ, Feng F. Reversible posterior leukoencephalopathy syndrome induced by bevacizumab plus chemotherapy in colorectal cancer. World J Gastroenterol. 2014;20(21):6691-7. https://doi.org/10.3748/wjg.v20.i21.6691. 